\title{
De parques y naturalezas. Enunciados, cimientos y dispositivos
}

\author{
On Parks and Nature. Enuntiations, \\ Foundations and Mechanisms
}

\author{
Beatriz Santamarina Campos \\ Universidad de Valencia
}

\section{RESUMEN}

Desde nuestra perspectiva, los parques naturales presentan, tanto una oportunidad para reflexionar sobre los cimientos ideológicos de nuestra práctica cultural, como una invitación para poner en entredicho las políticas conservacionistas "neoliberales" presentadas y revestidas como ecológicas. Las áreas protegidas son un campo complejo de análisis, llevan procesos asociados de territorialización y desterritorialización, de homogeneización e hibridación, de terciarización, regulación y reurbanización, dentro de lo que se ha venido denominando la globalización. En este artículo abordamos la compleja expresión de los parques naturales. Para ello, nos acercaremos a las múltiples dimensiones de lo "natural", centrándonos en la política. Atenderemos a los dispositivos de configuración y legitimación de los espacios naturales como un primer marco de análisis y nos aproximaremos a la etnografía producida en nuestro país con el objeto de ver los procesos con los que se identifican hoy en día. Por último, planteamos los retos a los que se enfrentan las áreas naturales y el papel de la antropología como disciplina en este campo.

Palabras clave: Espacios naturales; Patrimonialización; Apropiaciones; Conflictos.

\section{SUMMARY}

This article takes the view that natural parks are as much an opportunity to pause for reflection on the ideological foundations of the way we live our culture, as they are an invitation to cast doubt on neoliberal conservationist policies dressed up as ecologicallyminded ones. Protected areas make for difficult analysis. They entail processes that are associated to territorialization and de-territirialization, to homogenization and crossbreeding, to tertiarization, regulation and re-urbanization, and so on, within what has come to be known as globalization. This way of exercising power leads to the regulation 
of nature through a variety of ways of mercantilization. This article looks at the complex expression of natural parks. To do so, we have approached the multiple dimensions of the "natural", focusing particularly on the political dimension. We have paid special attention to the mechanisms of configuration and legitimization of natural spaces, such as in the first framework of analysis, and we approach the ethnography produced in our country with the aim of looking at the processes with which they are identified nowadays. Finally, we consider the challenges facing natural areas and the role of anthropology as a discipline in this field.

Key Words: Nature areas; Heritage; Appropriations; Conflicts.

\section{INTRODUCCIÓN}

Al proponer una reflexión sobre los espacios naturales no estamos haciendo otra cosa que poner sobre la mesa la consideración conjunta de diversos aspectos que han sido abordados desde distintas disciplinas y desde diferentes perspectivas antropológicas. La producción etnográfica sobre parques naturales se ha disparado en los últimos años como se refleja en la extensa bibliografía aparecida (West et al. 2006), siendo uno de los campos más prolíficos en la actualidad. Varios factores explican este creciente interés. Por un lado, si nos asomamos a los datos ofrecidos por la UNEP (United Nations Environment Programme) a través de WDPA (World Database on Protected Areas) vemos cómo el crecimiento de los espacios naturales ha sido una constante en el mundo, sobre todo, a partir de la década de los 70 del siglo pasado (Santamarina 2005a). Este movimiento conservacionista global y globalizador, con múltiples consecuencias sociopolíticas y ecológicas, se ha convertido en un importante campo de trabajo. Además, la declaración de áreas protegidas ha recaído sobre 'zonas rurales remotas' donde los antropólogos han trabajado tradicionalmente, lo que ha contribuido a que las etnografías sobre las mismas se hayan multiplicado. Por otro lado, la incorporación en los debates antropológicos de los procesos de globalización y los conflictos medioambientales, junto al desarrollo de la ecología política, han permitido un giro sobre los intereses y los enfoques tradicionales (West y Brockington 2006). La propia crisis ecológica actual, que evidencia la necesidad de profundos cambios en un sistema que, en su funcionamiento normal y normalizado provoca un ecocidio y genocidio sistemático, ha generado un interesante volumen bibliográfico.

En nuestro país, este interés por las áreas protegidas se refleja, por un lado, en la aparición de investigaciones, seminarios y grupos de trabajo ${ }^{1} \mathrm{y}$,

\footnotetext{
${ }^{1}$ En este sentido, es significativa la constitución en los dos últimos Congresos Nacionales de Antropología, de un grupo de trabajo específico sobre espacios naturales,
} 
por otro, en las publicaciones conjuntas aparecidas en los últimos años que recogen distintos enfoques sobre los espacios naturales (Santana y Rodríguez 2002; Pascual y Florido 2005; Frigolé y Roigé 2006; Vaccaro y Beltran 2007; Beltran et al. 2008). Esta producción se enmarca también en el crecimiento imparable de las áreas protegidas en España, sobre todo, en los últimos años: "rara vez, en la historia reciente de nuestro país, hemos asistido a un proceso que afecte a una proporción tan elevada de territorio, y que se produzca, además de manera tan rápida” (Beltran et al. 2008: 12). Las cifras son contundentes en menos de dos décadas los espacios naturales protegidos se han incrementado exponencialmente: si en 1994 había 465, en diciembre del 2007 se contabilizan 1587 (Europarc 2008)².

Ahora bien, ¿Qué son los espacios protegidos? ¿Cuál debe ser su marco de análisis o qué fenómenos interrelacionados conllevan? Las preguntas que formulamos son tan sencillas como de difícil respuesta. La primera, desde un prisma institucionalista, es fácil de contestar, ya que se asumen global y acríticamente los criterios y definiciones de la International Union for Conservation of Nature and Natural Resources (UICN) para las áreas naturales. Aunque del manejo de los espacios naturales interesa sobre todo lo implícito, porque aproxima a la forma en que nuestra práctica ha trazado la(s) naturaleza(s) como dominio externo a partir de la constitución moderna que sostiene una división de mundos (naturaleza/cultura) (Latour 1993). Las áreas naturales encapsulan de forma magistral las contradicciones de nuestra praxis cultural, al fundarse éstas como modelos 'ecólogicos' sobre una máxima antiecológica.

La segunda cuestión nos sumerge en la complejidad. De forma evidente, las áreas protegidas son un campo enmarañado de análisis en la medida en que conllevan procesos asociados de territorialización y desterritorialización, de homogeneización e hibridación, de terciarización, regulación y reurbanización, etcétera, dentro de lo que se ha venido denominando la globalización neoliberal o el nuevo imperialismo (Petras y Veltmeyer 2002). Dicha práctica de poder, en última instancia, llevaría a la regulación de la 'naturaleza' a través de formas de mercantilización, es decir, la reduciría a mercancía insertándola en los circuitos del mercado global (Escobar 1995, 1996; Haraway 1995; y un largo etcétera).

Desde esta perspectiva, los parques naturales presentan, tanto una oportunidad para reflexionar sobre los cimientos ideológicos de nuestra práctica

aunque en anteriores se habían presentado comunicaciones sobre este tema, especialmente en el celebrado en Barcelona en el 2002.

${ }^{2}$ Esto sin contar con los espacios que integran la Red Natura 2000. Para más detalle ver Anuario de Europarc-España (2008). 
cultural (su enunciación se articula sobre conceptos fuertemente connotados y deificados: naturaleza versus cultura, cultura versus naturaleza), como una invitación para poner en entredicho las políticas conservacionistas 'neoliberales' (Igoe y Brockington 2007) presentadas y revestidas como ecológicas o medioambientales.

Pero, para una aproximación a la elaboración y construcción de los espacios naturales es necesario atender al menos a dos cuestiones previas. En primer lugar, hay que tener presente su origen y constitución, porque en gran medida la concepción decimonónica que los impulsó sigue hoy vigente. En el último tercio del XIX, se sitúa el origen de la constitución de la red de los primeros parques naturales, a los cuales se denominó de forma significativa National Parks. En los mismos podemos apuntar las primeras contradicciones y la dificultad de representar esferas antagónicas bajo la solución de un enunciado. Asimismo podemos ver los distintos paralelismos entre las activaciones patrimoniales culturales, encapsuladas en el denominado monumento nacional, y naturales, sintetizadas, en el parque nacional, así como los distintos procesos de musealización de ambos dominios y los procesos de apropiación y expulsión que conllevan. Más adelante veremos las múltiples paradojas con las que arranca este movimiento de conservación, ya que hoy en día son especialmente significativas porque muchas de ellas siguen presentes. En este sentido, no podemos dejar de señalar que la patrimonialización de la naturaleza es un proceso paralelo a la patrimonialización de la cultura que configura realidades discursivas y prácticas y que genera multitud de instituciones alrededor de procesos asimétricos caracterizados por los conflictos, las apropiaciones y los desplazamientos. Y que lleva, por tanto, a preguntarse, de forma forzosa, qué mecanismos se activan en cualquier restitución patrimonial y cuáles son los marcos de intervención sobre los que se asientan.

$\mathrm{Y}$ en segundo lugar, hay que atender a la expansión y normalización de los espacios naturales. En la actualidad, la proliferación y propagación de espacios declarados se enmarca en un contexto, tanto de crisis ecológica global, como de respuesta política fragmentada ante los riesgos generados por el sistema. Política que niega el conflicto ecológico, 'parchea' soluciones desintegradas y ostenta una hipermetropía necesaria para legitimar sus desplazamientos al futuro. Además, la profusión señalada se acompaña de la multiplicación de figuras proteccionistas y de órganos de gestión lo que añadiría, por un lado, complejidad en su análisis y, por otro, retórica disfrazada de políticas proteccionistas inoperantes (Santamarina 2008b). No en vano, muchos autores hablan de un fracaso institucional en la gestión de los recursos y en las políticas de conservación (Acheson 2006; Peterson et al. 2008).

En este artículo abordamos, en primer lugar, la compleja expresión de 
los parques naturales, donde el adjetivo natural coloniza el enunciado. Para ello, nos acercaremos a las múltiples dimensiones de lo 'natural' que se desprenden de nuestras prácticas y que tienden a ser ignoradas por el discurso hegemónico, pero que emergen en los escenarios de conflicto y en la lucha por definir los espacios. En segundo lugar, nos centramos en la dimensión política, haciendo una breve aproximación a la dualidad naturaleza/cultura, como constructo occidental cardinal. En tercer lugar, atenderemos a los dispositivos de configuración y legitimación de los espacios naturales como un primer marco de análisis. En cuarto lugar, nos aproximaremos a la etnografía producida en nuestro país con el objeto de ver los procesos complejos con los que se identifican hoy en día. Y por último, a modo de conclusión, planteamos los retos a los que se enfrentan las áreas naturales, así como el papel de la antropología como disciplina en este campo. Con todo, partimos de asumir dos premisas básicas. Primero, consideramos que los espacios naturales son esencialmente espacios políticos. Son un tipo de intervención de lo que podríamos denominar como 'gobernanza medioambiental', entendiendo la misma como "sinónimo de las intervenciones destinadas a introducir cambios en el medio ambiente relacionados con los incentivos, los conocimientos, instituciones, la toma de decisiones y comportamientos" (Lemos y Agrawal 2006: 298), es decir, el conjunto de procesos normativos, mecanismos y organizaciones que la atraviesan. Y, segundo, es necesario tener presente que "la conservación es un nexo de relaciones entre las grandes organizaciones y los donantes, entre organizaciones y gobiernos, entre científicos y la población local, y así sucesivamente" (Brosius 2006: 683).

\section{ENUNCIADOS: DE LA(S) NATURALEZA(S)}

Si algo ha de llamar nuestra atención es la particular forma en que denominamos a los espacios naturales como territorios susceptibles de protección e intervención. Bajo la versatilidad de las formas adoptadas (parque natural, reserva natural, monumento natural, etcétera), la fórmula más utilizada es la de aunar parque y natural. Es decir, los espacios naturales fusionan en su enunciado algo que se da como 'dado', lo natural, y algo que se percibe como 'construido', lo cultural. Aunque, en realidad, la 'cultura' aparece negada, implícita o explícitamente, subrayándose la naturaleza, y no cualquier naturaleza como veremos a continuación, como motor de su activación.

Atendamos a su formulación. El enunciado es tan sencillo como paradójico, al casar dos conceptos de difícil maridaje en nuestro sistema de cognición basado en un modelo jerárquico y antidialógico. El concepto parque, atendiendo a su etimología, hace referencia a 'terreno cercado', un espacio 
acotado, al cual se le imponen límites tan reales como simbólicos. Además, viene marcado, fundamentalmente, por la actividad recreativa desarrollada en el mismo. Ambas consideraciones, espacio cerrado y lúdico, nos acercan a su representación e ideología. Pero, ahora, lo que nos interesa retener es que en la enunciación de los espacios naturales, se obvia la explicitación de los parques (solo sirven para reconocer la imposición de la práctica cultural) y se entrona lo natural como calificativo conceptualmente colonizador. Es decir, el calificativo natural va más allá de matizar el primer concepto, lo coloniza y desplaza, de tal manera que substantiviza la fórmula empleada, dejando atrás el término parque que parece sólo como un mero recordatorio de nuestra voluntad de asentar límites o como preámbulo o fuerte prescriptor de lo que nos vamos encontrar (o deseamos encontrar). De facto, la complejidad y el dinamismo de los espacios naturales se ven obviados al trazar fronteras y demarcaciones conceptuales y reales.

Los espacios naturales configuran y representan el mundo de lo natural de una manera particular que obliga a prestar una especial atención a la construcción social de lo natural. La importancia que adquiere 'natural', y de una 'naturaleza' no cualquiera, es decir, connotada de atributos redundantemente 'naturales', fuerza a descubrir las múltiples dimensiones del complejo cultural 'naturaleza'. Resta decir que las percepciones de la(s) naturaleza(s) no sólo mudan en el tiempo sino también en el espacio (Descola y Palssón 1996) $)^{3}$. Los distintos saberes locales han significado, utilizado y diluido la 'naturaleza' a través de una variedad de prácticas. Eder (1996) ha señalado la importancia de atender a cómo en nuestra práctica cultural se construye la 'naturaleza', y cómo las ideas y las figuraciones que se tienen de la misma mediatizan las relaciones que la sociedad establece con la "naturaleza'. Así, la actual construcción social de la naturaleza en las sociedades modernas industriales explicaría la destrucción de la misma. El hecho de señalar que existe una construcción social de la 'naturaleza', pese a no ser ninguna novedad, posibilita una mejor comprensión de los espacios naturales. Al fin y al cabo, los mismos son una manera de construir nuestro mundo.

Ahora bien, no es fácil hablar de naturaleza cuando el recurso más utilizado para definirla en nuestra práctica cotidiana es que es 'natural'. Cabe plantearse entonces de qué platicamos cuando nos referimos al mundo de lo natural. Podría pensarse que la naturaleza es algo objetivo y real; una entidad propia, caracterizada por una esencia fundamental que la conforma

${ }^{3}$ La propia disciplina antropológica ha ido modificando su consideración: como proceso evolutivo en continuo, como esfera delimitada y contrapuesta, como sistema de flujos... (Santamarina 2008a). 
como tal, y que no necesita de subjetivación porque es tal cual es. Pero, la naturaleza no es 'neutra', ni 'dada', ni 'esencial', ni 'objetivable'. Estos son más bien atributos variables que podemos encontrar en distintos contextos discursivos. Nos detendremos, por un momento, en dos ejemplos para ilustrar a qué nos estamos refiriendo. El primero pone al descubierto un mecanismo gráfico de elaboración narrativa muy socorrido en nuestra práctica cultural. El segundo pertenece al campo de lo semántico, y nos invita a una reflexión sobre la utilización normalizada, en nuestro vocabulario común, de los usos derivados del concepto naturaleza.

En cierta medida la naturaleza se viene hoy edificando a través de un dispositivo parecido al de las culturas primitivas (Comas d'Argemir 1998). La imagen de los pueblos salvajes connotados de naturalidad ha alimentado durante largo tiempo nuestro pensamiento ${ }^{4} \mathrm{y}$, de hecho, hoy el mito del buen salvaje sigue vigente (Milton 2001; Descola 1998), ahora como el noble salvaje ecológico, produciendo interesantes debates acerca de la conservación y la sostenibilidad en las comunidades indígenas (Krech 2005; Hames 2007). Desde la melancólica búsqueda del 'estado de naturaleza', encontramos numerosos autores que han volcado en los 'pueblos elementales y naturales' un paternalismo benévolo que contribuyó a las ambiciones colonialistas. Pero la representación romántica del noble salvaje se corresponde hoy con la elaboración de una noble naturaleza. La búsqueda de espacios naturales vírgenes y la recreación forzada de lo natural (Frigolé 2007) es síntoma de una reconstrucción de un pasado idílico perdido. Resta decir que la realidad dista mucho de esta ficción.

Por otra parte, el recurso de 'lo natural' en nuestro día a día es tan habitual como significativo. En lo cotidiano, expresiones como 'es natural', 'naturalmente' o 'tener naturalidad' son utilizadas en numerosos contextos, apareciendo siempre con un denominador común: todas se califican de forma positiva. Cuando algo nos parece lógico y razonable decimos que es natural. Al mismo tiempo, cuando se nos presenta algo sin artificio le atribuimos la característica de natural. Si el desarrollo de un acontecimiento ha salido según lo previsto, decimos que todo ha transcurrido con naturalidad. Y, cuando alguien actúa o se expresa con desenvoltura o familiaridad decimos que es una persona natural. En contrapartida, también utilizamos estar desnaturalizado y, en este caso, los significados están tildados negativamente. Por ejemplo, cuando se falsifica o altera cualquier cosa, y con ello se le hace perder

\footnotetext{
${ }^{4}$ Pensemos un momento en el esquema teórico de Rousseau, considerado el primer romántico en el seno de la Ilustración. En su búsqueda del hombre en 'estado de naturaleza' (como recurso teórico hipotético) tomó como modelo, entre otros, a los pueblos primitivos (salvajes) por considerarlos más cercanos al mundo de lo natural.
} 
las cualidades asignadas originalmente, se dice que se ha desnaturalizado. Más contundente resulta el hecho de que se considere a alguien desnaturalizado al perder actitudes que se consideran innatas en referencia a su parentesco. Y, tradicionalmente, desnaturalizar también ha sido desterrar a alguien de su lugar de origen, privarlo de su referente inmediato y desligarlo de su ubicación original. Por no hablar de contra-natura o anti-natural.

Como vemos, la conceptualización de la naturaleza conduce a multitud de imágenes que la sitúan con unas características muy particulares, y que responden a un mapa de atribuciones y valores complejos. Así, la naturaleza es tanto un recurso retórico como un instrumento central en nuestro marco de intelección y en los procesos culturales se la construye a través de técnicas, instituciones, prácticas y discursos. Podemos entonces hacer un ejercicio de entendimiento para comprender sus múltiples dimensiones interrelacionadas. En primer lugar, la elaboración cultural de la naturaleza tiene una dimensión ontológica, en la medida en que se constituye como una herramienta fundamental para pensarnos en el medio y para dotarnos de identidad. La naturaleza es y no es, al mismo tiempo, parte esencial de nosotros mismos, y como referente básico pasa a ocupar una posición central a la hora de situarnos en el mundo. Al hablar de naturaleza no podemos pasar por alto que nos enfrentamos a una categoría esencial en nuestra forma de concebirnos. La naturaleza se convierte en pieza clave y en esquema de discernimiento a través de dicotomías que operan eficazmente en nuestra práctica cultural: cultura frente a naturaleza, salvaje frente a civilización, humano frente animal, alma frente a cuerpo5. En segundo lugar, la noción de naturaleza contiene una dimensión epistemológica al ofrecernos aspectos cardinales básicos, puesto que se alza como punto estratégico en la edificación de procesos tan fundamentales como la atribución de orden y la asignación de sentido. La naturaleza no es una esfera bien delimitada, ni un objeto aproblemático; más bien constituye un eje primordial de una cosmovisión del mundo que intenta dar respuesta a problemas tales como el orden y el desorden, el caos y la disciplina, la coherencia y el sentido. Asimismo, la naturaleza tiene una tercera dimensión simbólico-cognitiva, en cuanto se nos presenta como construcción social. La aprehensión de la naturaleza se realiza a través de la percepción, conceptualización y categorización en representaciones simbólicas que están dentro de un sistema más amplio de cognición. En el campo de lo cultural se elabora y reformula de forma constante a partir de la experiencia, y constituye una parte importante de su cosmología global. Así, en nuestros procesos culturales podemos

${ }^{5}$ A este respecto, es interesante el análisis sobre las metáforas primarias de Fernández (1993). 
ver cómo a través de la personificación se la disfraza o desnuda (madre, madrastra, etc.) y se le otorga un papel principal en el trazado de límites. Además, al ser utilizada como frontera se convierte en protagonista de valores. Las percepciones sobre la misma varían y sirven a menudo como fuente de litigios simbólicos y reales. En cuarto lugar, la naturaleza posee una dimensión ecológica, en la medida en que se nos manifiesta como escenario de vida. Al establecerse como medio se constituye tanto en recurso para la existencia como en una referencia imprescindible para nuestra ubicación en el mundo. La(s) naturaleza(s) se convierte en un entorno susceptible de transformaciones. De ahí las relaciones que se establecen con ella, aunque éstas sean percibidas en términos utilitaristas o funcionalistas, idealistas o materialistas. Y, por último, tiene una dimensión política, entendiendo que nos referimos a un término amplio, flexible y abarcador que incluye diferentes prácticas discursivas, tales como las sociopolíticas y las económicas. Pero al hablar de esta dimensión hacemos especial énfasis en el poder (el poder en su sentido más pragmático, como forma tradicional de imponer definiciones del mundo). Así, podemos observar cómo la "naturaleza" ha sufrido una inmensa tarea normalizadora, necesaria para la legitimación de modelos únicos de interpretación. El dominio de la "naturaleza", a través de mecanismos de subordinación, ha sido una constante en nuestro pensamiento occidental. Y es una expresión más de la morfología del poder, que reduce y conduce a los sujetos, objetos, individuos, sociedades y naturalezas a través de mecanismos de control (Santamarina 2008a). En este sentido, la dimensión política de la naturaleza, pone de relieve un entramado complejo a través del cual podemos observar cómo se han ido configurando los sentidos y cómo se manifiesta un dispositivo político clave: la naturalización de la cultura y la culturalización de la naturaleza. Y, a él, queremos dedicar una atención especial ya que el mecanismo de representación de los espacios naturales se asienta sobre la lógica de exclusión. Es decir, en la práctica y en el discurso nos encontramos reproducido el mismo marco de inteligibilidad, que sitúa en nuestra práctica cultural la 'naturaleza' y la 'cultura' como realidades diferenciadas y reificadas (exclusiones luego trasladadas a las prácticas de apropiación del territorio y de regulación de los usos).

\section{Cimientos ideológicos: De Dualidades}

En ese intento de no dar por hecho el mecanismo de lo evidente por sí mismo, entendemos que se hace necesario sacar a la luz las relaciones que atraviesan y sustentan las representaciones que dan sentido a los espacios naturales. En la formulación de los espacios naturales se dan por asumidas al menos dos consideraciones fundamentales: la 'naturaleza' es evidente 
(proceso de objetivación) y la "protección" es indiscutible (proceso de intervención). Es decir, la concepción se levanta sobre la propia constitución hegemónica de nuestra praxis cultural, en el corazón de la misma, que determina, entre otras, como esferas independientes la cultura y la naturaleza (Strathern 1980; Latour 1993; Descola y Palsson 1996; y un largo etcétera) a través de un modelo subordinado y sometido, lejos de modelos alternativos dialógicos y heterárquicos. Con ello, no negamos ni excluimos que existan otras formas de conceptualizar, entendemos que si algo caracteriza a dichos dominios ${ }^{6}$ es su carácter ambiguo, híbrido, polifacético y polifónico, donde se enfatizan y entrecruzan las distintas dimensiones de la(s) naturaleza(s). Pero al referirnos a discursos hegemónicos hablamos de los marcos universalizadores y homogéneos que conforman las férulas prácticas y discursivas (objetivas y subjetivas, reales y simbólicas).

La dualidad naturaleza/cultura es central no sólo porque se ha convertido en un mecanismo fundamental de aprehensión del mundo (asignación y distribución de sentidos) sino también porque su constitución hegemónica ha sido un eje fundamental para la legitimación de nuestro sistema. Pese a su carácter autoevidente, dicha dualidad parece no haber existido siempre? El desarrollo de la ciencia moderna, con la matematización del mundo y su visión mecanicista y materialista (Rifkin 1980; Botkin 1993; Shapin 2000), es clave para comprender el proceso de normalización y fiscalización de lo natural. De hecho, para Latour (1993) el rasgo distintivo de los modernos va a ser precisamente la separación entre el mundo natural y el mundo social, gracias a los procesos de purificación que se establecen ${ }^{8}$. La aparición y fortalecimiento del capitalismo temprano y el liberalismo, que sitúan a la razón burguesa (frente al sentido común) como dueña del progreso y el destino de la humanidad, no harán más que abundar en una visión de la naturaleza en la que ésta aparece sometida, controlada, mecanizada, cuantificable, mercantilizada y funcional.

La importancia de la ideología de la ciencia, que impregna todo el pensamiento occidental desde su constitución, fuerza, por un lado, a compren-

\footnotetext{
${ }^{6} \mathrm{Al}$ fin y al cabo, hemos incorporado en nuestro texto una ese entre paréntesis (s) detrás de cultura y naturaleza para mostrar, al menos como recurso, la heterogeneidad de los conceptos. Tan irreductibles como complejos. En este sentido, nuestro discurso no deja de caer en la trampa de la reificación.

7 Tal y como señala Pálsson, en el medievo europeo no había una separación radical entre naturaleza y sociedad; fue a lo largo del Renacimiento cuando se empezó a transformar dicha visión (1996: 65).

${ }^{8}$ Con todo, para Latour (1993), nunca hemos sido modernos, ya que la ciencia moderna nunca ha cumplido la máxima del modelo dualista al multiplicar híbridos de la naturaleza y la cultura.
} 
der los mecanismos que enaltecen ciertas praxis y discursos (Woolgar 1991; Haraway 1995; Latour y Woolgar 1995; Maffesoli 1993 y 1997) y, por otro, a entender su lógica dentro de los procesos de construcción hegemónica que conducen a una sociedad marcada por la dualidad en el pensamiento (naturaleza/cultura, cuerpo/mente, objeto/sujeto, etc.) y en el discurso (científico/ sentido común) y por una racionalidad política, económica y social que conlleva un imperialismo y un reduccionismo con dimensiones cognitivas y sociopolíticas. No es extraño, por tanto, que la antropología haya tardado tanto en desmantelar la dicotomía naturaleza/cultura (Descola y Palsson 1996), ya que la misma se sitúa en la médula que articula y alimenta al sistema.

De todo ello interesa retener dos aspectos. Por una lado, la dualidad naturaleza/cultura fortalecida por la constitución de la ciencia moderna (con la matematización y reducción de lo natural) y la consolidación de la economía (con la mercantilización y la comercialización de la naturaleza) sigue condicionando nuestro modo de representar el mundo de la naturaleza. De facto, con la era neoliberal y el neocapitalismo estamos asistiendo a viejas-nuevas consagraciones, como son: la vuelta al orden fundado, esta vez, en la máxima de la seguridad (frente a riesgos sociales, ecológicos y económicos); la fe en la verdad de la ciencia y la técnica como portadores del futuro (frente al presente); y la mercantilización de la naturaleza a través de una doble consideración: como recurso para la producción y como producción de productos con el valor añadido de lo "natural". Y, por otro, dicha dicotomía sigue funcionando como un potente imaginario en el discurso hegemónico al constituirse en una práctica efectiva para el control, a través de su reificación y construcción objetiva? ${ }^{9}$. Desde nuestro punto de vista, la máxima expresión de la dominación de la "naturaleza", reducida paradójicamente a "naturaleza", la encontramos en los lugares declarados parques naturales, como exhibiciones y reductos de espacios sagrados, sacralizados y sacrificados.

Sin duda, las políticas medioambientales, que impulsan la protección de la naturaleza, se articulan sobre la visión simplista y dualista (naturaleza/ cultura) que refuerzan y entronan a través de la profusión reiterativa (en distintas versiones, ora espacios naturales ora desarrollo sostenible). Y quizás para entender mejor esa profusión es necesario atender a los mecanismos de configuración que hicieron posible la creación de las áreas protegidas y su posterior expansión y normalización.

9 Es decir, "la estrategia de reducción para el control y la destrucción de la(s) naturaleza(s) y de la(s) cultura(s) se ha basado en una edificación objetiva de estas realidades como objetos transaccionales y como sujetos de apropiación lícita. La legitimación sobre el(los) otro(s) ha pasado por estrategias de subordinación que incluían su confinamiento como paso necesario para su colonización” (Santamarina 2008a: 178). 


\section{Dispositivos DE CONFIGURACIÓN: LOS ESPACIOS NATURALES}

Nuestra intención al hablar de configuraciones hegemónicas pretendía situar en una posición de salida las reflexiones acerca de los dispositivos ideológicos que han permitido la legitimación y multiplicación de los espacios naturales en un contexto de degradación ecológica global y de radicalización de la modernidad. La expresión parque natural sintetiza, como venimos apuntando, de forma magistral, el mentís que implica la compartimentación de dominios brindando una oportunidad para rastrear cómo hemos trazado como dominio externo la(s) naturaleza(s). Y es que, sin duda, el género de ser un 'otro', el atributo de su externalización y el carácter de su cuantificación es el que ofrece la posibilidad de constituir la(s) naturaleza(s) como campo de fiscalización a través de constantes mediaciones. Ahora bien, ¿Qué naturaleza(s) es susceptible de ser activada? O dicho de otro modo, ¿Qué naturaleza(s) debe ser acotada y patrimonializada para generaciones futuras siguiendo el argumento de las activaciones patrimoniales? La respuesta dada es tan 'natural' como 'naturalizada': se debe conservar la natural naturaleza. En este sentido, advertíamos, que no era una naturaleza cualquiera sino una natural naturaleza naturalizada. La construcción de esta concepción basada en una triada tautológica es especialmente interesante, porque se constituye en el propio mecanismo normalizador y legitimador de los espacios naturales y se sitúa en origen de los mismos.

El primer parque nacional del mundo, Yellowstone (EEUU, 1872), respondió a una politización temprana de la naturaleza basada en una idealización de lo que se consideraba como un paraíso perdido y supuso el arranque en la creación internacional de los espacios naturales (Riechmann y Fernández Buey 1994; Stevens 1997) ${ }^{10}$. La naturaleza original representada como 'naturaleza salvaje', verdadera en cuanto había sido inviolada, se transformó en el principal principio de activación. El pasado, en versión naturaleza prístina, se convirtió en escudo frente a los intensos cambios experimentados y en herramienta para la construcción de identidades (Lowenthal 1998). Ese pasado extraño y reinventado (Hobsbawm y Ranger 1988) será el motor de los primeros movimientos patrimoniales (naturales y culturales siguiendo la lógica practicada) ligados a la constitución de la primera modernidad y a los procesos de producción, destrucción y aceleración asociados a la misma (Ballart 1997; Santamarina 2005b). La consagración de la catedral de

\footnotetext{
${ }^{10}$ Desde finales del XIX y principios del xx, la corriente conservacionista se irá extendiendo impulsada por el proteccionismo aristocrático y el ambientalismo burgués y obrero, por los movimientos naturalistas y románticos, por el incipiente desarrollo de la disciplina ecológica, etcétera (Santamarina 2006).
} 
la Wilderness suponía la protección de espacios naturales para admirar 'en vivo el espectáculo' de la natural naturaleza (Descola 2007), una suerte de museos 'in situ' para preservar un pasado mitificado, intervenido y ennoblecido ${ }^{11}$.

Ahora bien, la importancia atribuida a Yellowstone, como modelo conservacionista fundamental para la preservación de la biodiversidad, lo que ha venido a llamarse finalmente patrimonio natural, ha ocultado las propias contradicciones en las que incurría el modelo y, lo que es más importante, ha negado el desahucio sobre el que se articuló su puesta en marcha. Lo que podríamos denominar, siguiendo a Biersack (1999), como el primer tipo de ecoviolencia. La reinterpretación de la historia de las áreas protegidas en EEUU ha puesto en evidencia cómo para mantener la esencia de la "América salvaje" no se ha explicitado lo que podría haber sido un sistema de contención y expulsión de los indios impulsado por las elites del Este norteamericano (Stevens 1997; West et al. 2006). En este sentido, Yellowstone, Yosemite (1890), Sequioa (1890), General Grant (1890) y Mount Rainier (1899) trazarían un mapa hacia la hostilidad indígena y dibujarían una política nacional que perseguía confinar a los indios en reservas (Stevens 1997). $\mathrm{Y}$, podríamos añadir, refleja el proceso de legitimación de los proyectos nacionales a partir de la triangulación de la patrimonialización de la historia, la naturaleza y la tradición (Prats 1997).

Con todo, nos interesa retener dos aspectos fundamentales e interrelacionados de la concepción decimonónica articulada sobre el paradigma cultu$\mathrm{ra}$ /naturaleza. En primer lugar, dicha conceptualización, desde su origen, evidenció claras contradicciones. Por una parte, su consagración se asentaba en la negación de la historia de los indios americanos (naturaleza prístina lejos de la intervención humana), pero al mismo tiempo que eran borrados fueron más tarde recuperados para el entretenimiento (West et al. 2006: 260). En este sentido, Stevens (1997) considera una ironía que Yellowstone se convirtiera en el modelo internacional de los parques nacionales, basado en la naturaleza salvaje y deshabitada, por el parque siempre estuvo habitado $^{12}$ por distintos grupos indígenas que dejaron su impronta en el paisaje hasta que finalmente fueron expulsados hacia finales de 1880. Sin embargo, fue el símbolo de la protección estricta de la naturaleza y su patrón tuvo gran repercusión en la creación de los primeros parques internacionales. Y

${ }^{11}$ En Europa, encontramos un paralelismo significativo en el impulso de los primeros parques de la vida tradicional escandinavos dentro de esta primera ola patrimonializadora.

12 Stevens (1997) señala que hay constancia de que el territorio fue ocupado desde hace once mil años. 
por otra parte, la construcción se basó en una naturaleza sin seres humanos, pero para ser visitada, disfrutada y contemplada por seres humanos (Selmi y Hirtzel 2007: 12). La única actividad permitida será la turística (Stevens 1997). Lo que inauguró, a su vez, una particular mercantilización de la naturaleza a través del ocio y el consumo. En segundo lugar, con Yellowstone se instaura un patrón que pivota sobre dos premisas: "sirve como modelo para los esfuerzos conservacionistas" y "para la desposesión de indígenas en todo el mundo" (Spence 1999 citado en West et al. 2006: 258). De hecho, los primeros parques declarados en el mundo se concibieron como áreas en las que desaparecían las actividades humanas (caza, pesca, recolección, etc) lo que supuso la expulsión de muchos indígenas de sus tierras (Stevens 1997). De ello se desprende que este inicial proteccionismo se asentara en una política de conservación de la naturaleza guiada por una mezcla de intereses, patrimoniales, estéticos y recreativos y afianzada a través de mecanismos de expulsión y regulación del territorio. Política en la que se antepusieron los intereses hegemónicos a los criterios ecológicos, negando una triple evidencia: el fluir de la vida no es irreductible ni estático, los espacios son siempre mediados y la biodiversidad no es natural ni biológica. No es extraño que esta historia de la conservación, la más incómoda, no haya sido sacada a relucir. Al fin y al cabo, ha primado la idea de la preservación como necesidad prioritaria, sin cuestionarse los medios para alcanzar la misma.

Dicha premisa fue la responsable del inicio de la institucionalización de los espacios naturales que arrancó, sobre todo, con la creación de la International Union for the Protection of Nature (IUPN) en 1947 por la ONU, más tarde reconvertida en UICN (1956). Esta institución ha sido fundamental en al menos dos sentidos: por su labor para la conservación de la naturaleza, entendiendo que la conservación es inherentemente política (Brosius 2006), y por su trabajo para la definición y el establecimiento de categorías de espacios naturales. Esto último es especialmente interesante porque de la descripción de las distintas áreas protegidas, se desprenden importantes cuestiones ideológicas y prácticas. De las primeras, se hace evidente la exportación y colonización de modelos cognitivos (Stevens 1997; Kottak 1999; Brosius 1999b; y un largo etcétera). La dualidad naturaleza/cultura se despliega como único modelo interpretativo, imponiendo un único paradigma global, que obvia y destruye, en muchos casos, la diversidad de conocimientos locales que no siguen esta distinción, como ha puesto de manifiesto de forma relativamente reciente la etnografía (Descola y Palsson 1996; Hornborg y Pálsson 2000). Además, recordemos que el propio modelo dualista entorpece la visión ecológica al separar dominios. De las segundas interesa retener que las "categorías descriptivas terminan por tener efectos materiales" 
(West y Brockington 2006: 610). Pensemos que la variedad de categorías manejadas por la UICN representan en realidad diferentes grados de intervención humana. Lo que implica importantes regulaciones en los territorios (usos y recursos).

El trabajo normativo realizado por la UICN comenzó en 1969 (X Asamblea General de la UICN, Nueva Delhi) con la definición de parque nacional: "Son áreas relativamente amplias, donde uno o varios ecosistemas no se han visto materialmente alterados por la explotación y ocupación humana, donde las especies vegetales y animales, las formaciones geomorfológicas y los hábitats, son de especial interés científico, educativo y recreativo, o contienen un paisaje natural de gran belleza; donde la máxima autoridad competente del país ha tomado las medidas para prevenir o eliminar lo antes posible la explotación u ocupación de todo el área, y para hacer cumplir de modo efectivo el respeto por los rasgos ecológicos, geomorfológicos y estéticos que motivaron su establecimiento; donde se permite entrar a los visitantes bajo condiciones especiales, con propósitos de inspiración, educativos, culturales y recreativos". En la misma se puede ver cómo se asumía la definición decimonónica sin apenas variaciones, asentándose sobre el paradigma dualista. Tres años después de la definición se producía el primer reconocimiento de los espacios naturales como Patrimonio Mundial (Conferencia de París, 1972). La distinción de la UNESCO del patrimonio natural $^{13}$, como Patrimonio de la Humanidad, fortalecía, de nuevo, la dicotomía naturaleza/cultura y respaldaba la fórmula de los parques nacionales al otorgar a los mismos, de forma mayoritaria, la nueva distinción creada.

Casi diez años después de la definición de parque, la UICN publicaba el informe sobre Categorías, objetivos y criterios para las áreas protegidas (1978), realizado por la Comisión de Parques Nacionales y Áreas Protegidas $(\mathrm{CNPPA})^{14}$. En el documento se definían diez áreas de manejo ${ }^{15}$ y se mantenía la definición de parque, asumida en Nueva Delhi. De entre ellas desta-

${ }^{13}$ A partir de la definición de bienes naturales, catalogados bajo tres criterios: los monumentos naturales constituidos por formaciones físicas y biológicas, las formaciones geológicas y fisiográficas y los lugares naturales o las zonas naturales estrictamente delimitadas.

${ }^{14}$ Junto a la UICN, en la labor de descripción de categorías, es necesario señalar el programa MAB (Hombre y Biosfera) desarrollado por la UNESCO en 1971, que creó la categoría de 'Reservas de la Biosfera'.

${ }^{15}$ I Reserva científica/ Reserva natural estricta; II Parque nacional; III Monumento natural; IV Reserva de conservación/ Reserva natural manejada/ Santuario de vida silvestre; V Paisaje protegido; VI Reserva de recursos naturales; VII Áreas de biota natural/ Reservas antropológicas; VIII Áreas de uso múltiple; IX Reserva de la biosfera y X Lugares del Patrimonio Mundial. 
ca la distinción de 'Reservas antropológicas', quizás como un guiño a lo que muchos reclamaban, pero los seres humanos quedaban en 'algunas' áreas naturales. Fue el primer paso hacía el reconocimiento de los conocimientos locales, aunque hay que esperar a la década de los noventa para encontrar un salto cualitativo en la formulación de los espacios naturales. En el IV Congreso de Mundial de Parques Nacionales y Áreas Protegidas (Caracas, 1992) se redefinieron las áreas naturales, estableciéndose un amplio consenso en su descripción como "un área de la tierra y/o del mar dedicados especialmente a la protección y al mantenimiento de la diversidad biológica, y de recursos naturales y culturales asociados y manejados por medios legales u otros medios eficaces". La definición sufría así una significativa transformación: desaparecía la premisa instaurada por Yellowstone ("no se han visto materialmente alterados por la explotación y ocupación humana") contemplándose "recursos naturales y culturales asociados". Este giro copernicano, se concretó en la sustitución poco a poco de parque por área protegida (Stevens 1997). En consonancia con este cambio, en 1994 aparecía una nueva clasificación, Directrices para las Categorías de Manejo de Áreas Protegidas, en las que se identificaban seis áreas de manejo ${ }^{16}$. En realidad, las cinco primeras categorías prácticamente se mantuvieron y se intentó simplificar la terminología y hacer más flexible el sistema de clasificación, incorporando las áreas marinas que habían sido relegadas. Y en el Congreso Mundial de la Naturaleza de 1996, pese a la resistencia de muchos países, se reafirmaba este giro político reconociendo a las comunidades locales su derecho a participar en el manejo de los espacios naturales.

De forma evidente, desde los primeros intentos de definición hasta ahora es posible ver importantes transformaciones en los conceptos manejados que reflejan: las nuevas maneras de conceptualizar las áreas protegidas, y la(s) naturaleza(s); las luchas de muchos grupos por estar representados en una definición institucionalizada que les excluía; y el nuevo contexto de crisis medioambiental. De hecho, la crisis ecológica ha impulsado los espacios naturales como praxis conservacionista y, en la actualidad, dicha práctica se ha visto fortalecida por la segunda ola patrimonializadora de la modernidad avanzada y por el empuje obtenido por distintas conferencias y conve-

${ }^{16}$ I Reserva Natural Estricta/Área Natural Silvestre: Protección estricta con fines científicos/ fines de protección de la naturaleza salvaje; II Parque Nacional: Ecosistema para conservación y recreo; III Monumento Natural: Conservación de características naturales específicas; IV Área Ordenación de Hábitat / Especies: Conservación y gestión a través de una ordenación activa; V Paisaje marítimo-terrestre Protegido: conservación y recreo; y VI Área protegida de Ordenación de Recursos: Ecosistemas naturales para uso sostenible. 
nios internacionales que la han situado como un campo de intervención fundamental.

Desde su creación, nadie ha puesto en duda su necesidad, aunque sí se han cuestionado las lógicas y modos desplegados para la preservación. Pese a los avances reseñados en los noventa, las demandas de muchos grupos tan sólo se resolvieron en una declaración de 'buenos' principios y en un cambio terminológico que no condujo a una implementación real en el manejo de los espacios naturales. En juego había demasiados intereses, desde la propiedad de la tierra hasta la propia concepción de la conservación. Muestra de este fracaso fueron las voces que se alzaron en el V Congreso Mundial sobre Parques de Durban (2003), rechazando los actuales modelos de conservación transnacionales (políticos, conservacionistas y científicos) y poniendo sobre la mesa muchos de los supuestos básicos de la conservación ${ }^{17}$. En realidad, la patrimonialización de la naturaleza se ha caracterizado por los mismos procesos de exclusión de cualquier activación patrimonial. Los espacios naturales permiten ver las relaciones de dominación que existen tras su conformación histórica. Relaciones de poder, fundamentalmente, asimétricas, donde afloran disputas materiales (propiedad, recursos y usos) y simbólicas (identidad) entre clases, géneros, grupos y etnias. De tal forma que las desigualdades estructurales (locales, nacionales y globales) pueden ser observadas en las formas de apropiación de los espacios naturales. Así, no es raro que los intensos procesos de patrimonialización natural se hayan visto acompañados por numerosos conflictos al estar plagados de negaciones, algo que es visible a lo largo y ancho del planeta (Brockington y Igoe 2006; West et al. 2006; Pascual y Florido 2005; Selmi y Hirtzel 2007; Igoe y Brockington 2007; Beltran et al. 2008) y que responde a la imposición de un único modelo de conservación. De esta forma, hoy en día, como veremos a continuación, pese a las transformaciones señaladas, en la protección de las áreas naturales podemos encontrar vigente el esqueleto decimonónico sobre el que se conformó la conservación de la naturaleza.

${ }^{17}$ Lo sorprendente de la cumbre, como señala Brosius (2004), fue la numerosa presencia y la voz de grupos indígenas y comunidades locales que subrayaron que estaban a favor de la conservación pero no de las formas que les excluían y marginaban. Este protagonismo, molestó a muchos. Brockington e Igoe (2006) recogen las quejas de Terborgh (2004), quien se lamentaba de que en la conferencia las discusiones sobre la pobreza, la injusticia social, los derechos de los pueblos, etc., habían desplazado la conservación de la vida no humana en el planeta (de nuevo, la estrechez de la mirada). Las conclusiones de la conferencia muestran estos cambios (UICN, 2005). 


\section{ETNOGRAFÍA DE LOS ESPACIOS NATURALES EN ESPAÑA}

Si bien es cierto que las políticas conservacionistas se han ido flexibilizando conforme han sido objeto de análisis y de crítica, y en la medida que han cobrado voz actores antes vedados, no deja de ser menos cierto que las mismas siguen asentadas sobre dos de los pilares de la constitución moderna. Por un lado, en la dicotomía naturaleza/cultura, donde la naturaleza, en aras de la biodiversidad sigue representándose bajo la natural naturaleza $^{18}$. Y por otro, en la distinción conocimiento científico/conocimiento común, donde el conocimiento técnico-científico es el soporte para las políticas de conservación 'verdaderas', desplazando así, y de forma legítima, a los conocimientos locales.

Podemos ver estos aspectos reflejados en la bibliografía etnográfica producida sobre espacios naturales en España. Algunos autores señalan que la propia legislación, estatal o autonómica, sobre espacios naturales y los pretendidos Planes de Ordenación de los Recursos (PORN) y Planes de Regulación de Usos y Gestión (PRUG), cuando los hay, evidencian una política reduccionista basada en la dualidad naturaleza/cultura (Coca y Díaz 2005; Coca y Quintero 2006; Santamarina 2008b; Coca 2008). Las normativas, explícita o implícitamente, reifican y construyen los dominios natural y cultural como independientes, con las consecuentes derivaciones prácticas (prescripciones y prohibiciones). Esta política de redefinición del territorio, más allá de lo discursivo, provoca expropiaciones, apropiaciones y reapropiaciones en contextos tradicionalmente marginados.

Desde su comienzo ${ }^{19}$, estos procesos se han venido caracterizando por su imposición, es decir, se han asentado en políticas diseñadas 'desde arriba' (Santamarina 2005b), que se basan "en el modelo vertical (top-down)" (De la Cruz y Pascual 2005: 97) caracterizado por una "excesiva centralización en la toma de decisiones" que responde "al propio modelo de gestión

\footnotetext{
${ }^{18}$ En este sentido, las categorías de la UICN no dejan de ser una gradación, de más a menos, de los espacios considerados más naturales. Del mismo modo, la globalización del patrimonio (patrimonio de la humanidad) sigue perpetuando esta concepción al apuntalar las categorías cultural/natural, al redistribuir de forma asimétrica las distinciones y al reforzar la concepción decimonónica (el $50 \%$ de las nominaciones de patrimonio natural recae en los parques).

${ }^{19}$ En España los primeros parques nacionales (Covadonga y Ordesa) fueron declarados en 1918, gracias a la iniciativa del Marqués de Villaviciosa y desde el principio estuvieron plagados de conflictos con sus vecinos (Santamarina 2005b). De hecho, la Ley de Creación de Parques Nacionales de 1916, aunque escueta, tan sólo contenía tres artículos, fue una de las primeras en desarrollarse en Europa. La misma respondió a distintos intereses conservacionistas (Muñoz Flores 2006).
} 
implementado en el diseño institucional" (Cabrera y Cabrera 2005: 122). Además, "históricamente, la declaración de los espacios naturales protegidos se ha efectuado mediante el procedimiento de urgencia, lejos de plantearse en términos de un proyecto comunitario" (Carbonell 2007: 65). De hecho, la participación de las poblaciones locales afectadas, en la declaración de un espacio, suele ser "extremadamente limitada" (Pascual et al. 2005: 59), más simbólica que real. A menudo sus peticiones son ignoradas (De la Cruz y Pascual 2005; Coca 2008) o se sustentan en "un mero trámite burocrático y no como una apuesta real por el consenso social" (Corbacho 2005: 174). Salvo honrosas excepciones, como ocurre en las áreas marinas (Rodrigues y Pascual 2008) donde quizás la participación se deba más al carácter y propiedad de los recursos (Pascual y De la Cruz 2008), los procesos de participación social acaban convirtiéndose "en teatros" (Coca y Díaz 2005: 291).

La mayoría de las investigaciones realizadas ponen en evidencia la falta de interlocución entre los diversos grupos implicados y la exclusión que sufren las comunidades locales. En gran medida la exclusión viene justificada por una paradoja irónica: su desconocimiento 'verdadero' del entorno (Coca 2008) ${ }^{20}$. Aparece aquí una nueva jerarquización, la del conocimiento, entre los que saben y no saben, es decir, entre expertos y locales. Mientras que unos miran a los 'otros' como ignorantes, los otros ven a los 'de fuera' con hostilidad ante la competición por los usos y recursos (Batista 1999; Coca y Quintero 2006; Batista y Pascual 2005; Coca y Zaya 2008). La ordenación territorial se sustenta sobre criterios tecnoecológicos y, de esta manera, se borran los usos y la historia local (Coca 2002 y 2008). El resultado es un proceso definido por la distribución desigual de conocimientos que lleva pareja una distribución desigual de los recursos. El borrado tecnocientífico es una práctica de apropiación que se configura como un primer problema: "la mirada homogeneizadora del diseño técnico de los espacios protegidos" se convierte en "un primer factor que obstaculiza su desenvolvimiento" (Florido y Clavero 2008: 267). Dicho modelo homogeneizador, globalizador y hegemónico, de una parte, no permite puentes entre conocimientos que no son ni excluyentes, ni estancos y se asienta en una contradicción entre la descontextualización (prácticas científicas) y la contextualización (prácticas locales) (Pascual y Florido 2005; Florido 2005) y, de otra, responde a intereses y valores "a menudo externos y ajenos a las comunidades locales" (Beltran et al. 2008: 15).

Por otro lado, las normativas reconfiguran los espacios al tener la capa-

${ }^{20}$ Algo que ya se puso de manifiesto en las primeras declaraciones de parques naturales: había que frenar, según el marqués de Villaviciosa, a "esos salvajes españoles" (Fernández 1999). 
cidad no sólo de dictar qué es y no es la(s) naturaleza(s) sino de prescribir sus usos, qué se puede y no puede hacer (afianzadas ambas a través del modelo de conocimiento excluyente). Con respecto a la primera, la arbitrariedad y la subjetividad parecen regir en el proceso de asignación de lo que es la(s) naturaleza(s) (Duran 2002; Hernández 2008; Quintero et al. 2008), estableciéndose una premisa basada en una(s) naturaleza(s) 'poco explotada' "como si la explotación y apropiación de los recursos sólo se midiera por el grado de densidad urbana e industrial" (Hernández 2008:84) ${ }^{21}$. En la reconstrucción de esta imagen ideal podemos ver reproducidos los sistemas tradicionales de jerarquización del territorio y de subordinación (Quintana et al. 2008; Coca 2008). En este sentido, es interesante reseñar el trabajo de Vaccaro (2005) donde traza una genealogía política de la apropiación territorial en el contexto pirenaico. Desde su punto de vista es necesario atender a los procesos de territorialización del Estado español (la racionalización territorial, la expropiación de tierras y el control de los recursos naturales) iniciados hace doscientos años, para poder comprender las actuales áreas protegidas. Factores como la propiedad territorial, los límites administrativos, las infraestructuras y los recursos son necesarios para entender las lógicas de las políticas de las áreas naturales y de sus sistemas de protección. Al fin y al cabo, un parque supone el establecimiento de una nueva demarcación jurisdiccional sobre el territorio (Vaccaro 2006b, Vaccaro y Beltran 2007 y Beltran y Vaccaro 2007) y sobre él se despliegan posiciones de poder (Durán 2006; Quintero et al. 2008).

Por lo que respecta a la segunda, la regulación de las actividades, las normativas limitan los usos y recursos del territorio marginando e incluso negando las prácticas locales (Vaccaro y Beltran 2007; Coca 2008). En las normas, desaparecen algunas (prácticas calificadas de tradicionales, que pueden aparecer más tarde reinventadas) e introducen otras nuevas (prácticas calificadas de modernas o posmodernas). La nueva gestión política del territorio, sobre la que giran las expropiaciones prácticas, se funda en la promesa de una vieja conocida, la máxima del desarrollo. En este caso, revestida de local y sostenible. El desarrollo local/sostenible es un potente instrumento discursivo que se certifica con la necesidad y el interés general para la conservación como legado para el futuro (Hernández, 2008). Su puesta en marcha vendría dada por la activación patrimonial de la naturaleza (más tarde completada con la vertiente cultural). El valor o valores de lo "natural", adobados por la profusión de términos que ayudan a connotar el territorio (ecológico, rústico, rural, etcétera), se convierte en instrumento

${ }^{21}$ Es interesante señalar que el $73 \%$ del territorio español protegido se sitúa por encima de los 1500 metros de altitud (Europarc, 2008). 
central en el contexto de terciarización de la economía (Roigé 2006; Frigolé 2007). La expansión y democratización del turismo, las nuevas demandas de consumo patrimonial y la fiebre patrimonializadora a la que asistimos convierten a los espacios en mercancías preparadas para un consumo cada vez más exigente (Santana 2002; De la Cruz y Santana 2008; Hernández 2008). El territorio y los recursos naturales pasan de ser espacios de extracción y transformación a ser de contemplación, disfrute y tranquilidad (Vaccaro 2006b). El turismo y la demanda turística muta los espacios, apropiándose de los territorios a partir de una reconstrucción física, cultural y discursiva adaptada a las necesidades de los visitantes urbanos (Vaccaro 2005 y 2006a; Beltran y Vaccaro 2007; Coca y Quintero 2006), "se trataría de mercantilizarlos, convertirlos en objetos, en bienes de consumo para colmar las expectativas de los turistas" (Florido y Clavero 2008: 277). De tal forma que "la tendencia general del desarrollo histórico es que la población local, que vive 'en' la naturaleza, pasa progresivamente a vivir 'de' la naturaleza, de su uso, de su transformación, a vivir de los que vienen temporalmente a 'vivir en la naturaleza'" (Frigolé 2006: 26). En realidad este proceso "constituye una apropiación urbana del paisaje rural de acuerdo con las directrices productivas ofrecidas por la actual economía hipermoderna" (Vaccaro 2006a: 87). El resultado del mismo es la reconfiguración de las actividades económicas y redefinición de las identidades. En cuanto a las primeras, la creciente terciarización del territorio tiene resultados e impactos diferentes según los contextos: urbanización de los espacios rurales, construcción masiva de viviendas e infraestructuras, multiplicación de los servicios, etcétera (Vaccaro 2006b; Beltran y Vaccaro 2007; Hernández 2008). Los impactos generados por esta política volcada al turismo provocan multitud de impactos sobre un territorio, que recordemos, se quiere preservar. Y en realidad "expresa una propuesta mercantilista que hace difícil por sí misma la diversidad natural y cultural" (Florido y Clavero 2008: 277). De hecho, la fuerte presión urbanística, de segundas residencias y de infraestructuras, provoca actuaciones, en muchos casos ilegales y polémicas (Cabrera y Cabrera 2005; Sánchez Garrido 2008). Y llevaría, en algunos casos, a procesos de gentrificación por la fuerte demanda urbanizadora. Además, las nuevas estrategias y beneficios económicos, no recaerían sobre los locales produciéndose de nuevo una marginación (Coca 2008).

En cuanto a las identidades, hay que tener presente que las reproducciones locales están sujetas al "hecho de que una parte importante de su contenido, aún siendo de carácter local, ha sido elegido desde una perspectiva externa, por estar orientada hacia el exterior y por estar en buena parte gestionada por gente de fuera" (Frigolé 2006: 29). La imposición de una reinvención más rentable (mercantilización de la identidad), que sea acor- 
de a las expectativas e intereses de los turistas, obliga a desplegar medidas para recrear una imagen 'bucólica y pastoril' de acuerdo con los cánones impuestos. Para un espacio natural (naturaleza natural) se espera un pueblo naturalizado (naturalización de historias, gentes, tradiciones y memorias). Un todo sobresaturado, bien aderezado (Frigolé 2007; Beltran y Vaccaro 2007; Quintero et al. 2008).

Con todo, los estudios muestran que los espacios naturales son también una oportunidad política para el desarrollo local y la identidad en escenarios muy dinámicos (Hernández 2005; Beltran et al. 2008). En este sentido, los recursos se convierten en un campo de disputa, donde los distintos actores buscan su voz, produciéndose constantes mediaciones entre ellos (Quintana et al. 2008), aunque finalmente se vean desplazados. La etnografía realizada demuestra la extremada complejidad de los procesos de la patrimonialización de la naturaleza y la necesidad de convertir a la antropología en una herramienta clave para abrir diálogos hacia una gobernanza medioambiental basada en la participación, la diversidad y la restitución, frente a la exclusión, la homogeneización y la apropiación.

\section{CONCLUSIONES}

Para finalizar, es necesario realizar una reflexión conjunta sobre todo lo abordado. Desde nuestra perspectiva, las tesis conservacionistas impulsadas, bajo distintas lógicas, para las áreas naturales tropiezan de lleno con múltiples contradicciones insostenibles. En primer lugar, su articulación sobre la compartimentación de la naturaleza/cultura es una premisa antiecológica que niega las dinámicas ecosistémicas y, por ende, la imposibilidad de límites (alcance de los fenómenos transfronterizos como el calentamiento global, el deterioro de la capa ozono, la lluvia ácida, etcétera). En segundo lugar, su impulso como estrategia de desarrollo versus conservación reafirma el principio neoliberal del mercadeo de la naturaleza, provocando múltiples impactos socioecológicos (presión sobre el territorio, terciarización, urbanización, etcétera) y reduciendo la(s) naturaleza(s) a bien tasable, consumible y comerciable en el juego de intereses y beneficios. En tercer lugar, su expansión y crecimiento como modelo para preservar la biodiversidad presenta numerosas fisuras al chocar con la evidencia de una reducción cada vez mayor de la biodiversidad y de una degradación generalizada de los ecosistemas. No sólo se trata de una falta de recursos, planificación y gestión de las áreas protegidas, es decir, una buena gobernanza de las mismas, sino de la carencia real de políticas sostenibles. Y dicha carencia es difícil de solventar mientras no se reconozca que los desequilibrios ecosociales son el resultado normal y normalizado de un sistema afianzado en la distribu- 
ción asimétrica de relaciones y en la mercantilización de todo lo susceptible de ser objetivable (sujetos, naturalezas, culturas). Más que desajustes, el sistema se ajusta generando desigualdades y desequilibrios que difícilmente pueden ser resueltos con el confinamiento de espacios reinventados y puestos a su disposición. Así las cosas, los espacios naturales no pueden ser una buena opción política cuando se promueven como herramientas retóricas medioambientales aisladas sin políticas sustentables globales y locales; no pueden ser una buena opción social cuando se asientan sobre la apropiación y expropación de territorios, conocimientos y memorias; no pueden ser una buena opción científico-técnica cuando se construyen sobre criterios anticientíficos y excluyentes.

Realizar una crítica contundente a los espacios naturales y sacar a la luz los conflictos y paradojas que emergen tras ellos es poner el dedo en la llaga. Es decir, en un contexto marcado por la urgencia de solventar los problemas ecológicos — pérdida cada vez mayor de la biodiversidad, cambio climático debido a la acción humana, presión insostenible de los recursos, destrucción de tierras fértiles, degradación de los ecosistemas, aumento de las desigualdades y un largo etcétera (Evaluación de los Ecosistemas del Milenio 2004; IPCC 2007; PNUMA 2007; PNUD 2007)—, puede resultar baladí e irresponsable, y contraproducente para algunos, no dar por hecho su necesidad. No es extraño que la crítica a la construcción de los espacios naturales se perciba como hostil para la conservación (Brosius 2006; Brockington et al. 2006). Además, teniendo en cuenta, que defender las áreas protegidas no sólo es un valor en alza y un deber ético, sino que hoy se encierran en el discurso de lo políticamente correcto, osar a cuestionarlos puede ser fácilmente malinterpretado. Brosius (2006) apunta a que las críticas vertidas por los antropólogos suelen ser mal recibidas e incluso se ven como un 'lujo' que los conservacionistas no pueden permitirse: "se considera que los antropólogos están tocando la lira mientras Roma arde en llamas" (2006: 683). No es extraño, entonces, que sean percibidos como corrosivos e irresponsables ${ }^{22}$. Parafraseando a Haraway, Brosius (2006) señala que los antropólogos y conservacionistas debemos establecer "colaboraciones situadas", a partir de los nexos que nos unen (la lucha contra un mundo homogéneo). La solución pasa por vincular la crítica al compromiso, contribuyendo a ofrecer alternativas con una participación activa en los procesos.

En este sentido, quizás convenga decir y afirmar con contundencia que estamos a favor de la conservación y protección del mundo, de su riqueza y diversidad, para resituar nuestro discurso. Pero eso no puede dejar de lado

${ }^{22}$ Además, hay que añadir que a veces los propios antropólogos se convierten en la voz de comunidades locales. 
el compromiso político-académico de denunciar los desequilibrios ecosociales que muchas veces se endulcoran o se tergiversan presentándonos una ficción lejos de la cruda realidad. De ahí, la necesidad deconstruir los pilares en los que se asientan las áreas naturales para empezar a construir nuevas bases sobre modelos dialógicos y heterárquicos basados en una pluralidad de conocimientos locales y multisituados, de espacios y memorias. Nuevos modelos de gobernanza medioambiental polifónicos, donde no se haga necesario hablar de 'ecologías de la coexistencia' porque se construyan los lugares como un campo integral de mediaciones y donde los esfuerzos se aúnen por legitimar la diversidad y la diferencia como praxis ecopolítica de otro mundo posible.

\section{BIBLIOGRAFÍA CITADA}

Acheson, J. M. 2006. "Institutional failure in resource management". Annual Review of Anthropology 35: 117-134.

Ballart, J. 2002. El patrimonio histórico y arqueológico: Valor y uso. Barcelona: Ariel.

Batista Medina, J. 1999. "Recursos naturales, comunidades y estado: una relación compleja”, en Narotzky, S., Galván, A. y U. Martinez (coords.), Antropología y economía politica: 57-67. Santiago de Compostela: FAAEE.

Batista, J. y J. Pascual, J. 2005. "Espacios protegidos, pescadores y estado: la participación local en la reserva marina de La Palma (Islas Canarias)", en Pascual, J. y D. Florido (coords.), ¿Protegiendo los recursos?: 63-82. Sevilla: FAAEE.

Beltran, O. y I. Vaccaro, I. 2007. "El paisaje de Pallars Sobirà: pastores, centrales eléctricas y estaciones de esquí", en Vaccaro, I y Beltran, O. (eds.), Ecología política de los Pirineos. Estado, Historia y Paisaje: 139-156. Barcelona: Garsineu Edicions.

Beltran, O., J. Pascual y I. Vaccaro (coords.). 2008. Patrimonialización de la naturaleza. El marco social de las políticas ambientales. Donosti: Ankulegi.

Biersack, A. 1999. "From the 'New Ecology' to the New Ecologies". American Anthropologist 101 (1): 2-18.

Botkin, D. 1993. Armonías discordantes. Una ecología para el siglo XXI. Madrid: Acento.

Brockington, D. y J. Igoe. 2006. "Eviction for Conservation: A Global Overview". Conservation and Society 4 (3): 424-470.

Brockington, D., J. Igoe y K. Schmidt-Soltau. 2006. "Conservation, Human Rights, and Poverty Reduction". Conservation Biology 20 (1): 250-252.

Brosius, P. 1999a. "Anthropological engagements with environmentalism". Current Anthropology 40 (5): 277-309.

Brosius, P. 1999b. "Green Dots, Pink Hearts: Displacing Politics from the Malaysian Rain Forest". American Anthropologist 101 (1): 36-57.

Brosius, P. 2004. "Indigenous Peoples and Protected Areas at the World Parks Congress". Conservation Biology 19 (3): 609-612.

Brosius, P. 2006. "Common Ground between Anthropology and Conservation Biology". Conservation Biology 20 (3): 683-685.

Cabrera, G. y A. Cabrera. 2005. "La Reserva Marina de la Isla Graciosa (Islas Canarias): Pescadores, turistas y políticas de protección”, en Pascual, J. y D. Florido (coords.), ¿Protegiendo los recursos?: 103-124. Sevilla: FAAEE. 
Carbonell, X. 2007. "Conflictos socioambientales en la planificación y la gestión de los recursos naturales en el Pirineo Aragonés", en Vaccaro, I. y O. Beltran (eds.). Ecología política de los Pirineos. Estado, Historia y Paisaje: 61-76. Barcelona: Garsineu Edicions.

Coca A. 2002. "Espacios naturales en Andalucía y Desarrollo rural", en Santana, A. y S. Rodríguez (coords.). Recreaciones medio-ambientales, políticas de desarrollo y Turismo. Barcelona: FAAEE.

Coca, A. 2008. Los camperos. Territorios, usos sociales y percepciones en un espacio natural andaluz. Sevilla: Fundación Blas Infante.

Coca, A. y A. Díaz. 2005. "Protección ambiental y percepciones locales en los parques de Andalucía”, en Pascual, J. y D. Florido (coords.). ¿Protegiendo los recursos?: 177192. Sevilla: FAAEE.

Coca, A. y V. Quintero. 2006. "Los de fuera claman naturaleza ¿Qué claman los de dentro", en Valcuente del Río, J. y L. Cardia (coords.), Territorializaiçao, Meio Ambiente e Desenvolvimiento no Brasil e na Espanha, 319-348. Brasil: Universidade Federal do Acre.

Coca, A. y Z. Zaya. 2008. "Protección ambiental, turismo cinegético y colectivos locales", en Beltran, O., J. Pascual y I. Vaccaro (coords.). Patrimonialización de la naturaleza. El marco social de las políticas ambientales. 115-130. Donosti: Ankulegi.

Comas D’Argemir, D. 1998. Antropología económica. Barcelona: Ariel.

Corbacho, M‥ 2005. "El paisaje percibido. Modelos de representación de la ensenada de Bolonia (Parque Natural del Estrecho Gibraltar)", en Pascual, J. y D. Florido (coords.), ¿Protegiendo los recursos?: 157-177. Sevilla: FAAEE.

De la Cruz, R. y J. Pascual. 2005. "Reservas marinas, ¿herramientas de gestión pesquera", en Pascual, J. y D. Florido (coords.). ¿Protegiendo los recursos?: 83-102. Sevilla: FAAEE.

De la Cruz, R. y A. Santana. 2008. "El turismo de Buceo en la Restinga (Islas Canarias) y L'Estartit (Cataluña): APMs, clasificaciones e impactos", en Beltran, O., J. Pascual y I. Vaccaro (coords.). Patrimonialización de la naturaleza. El marco social de las políticas ambientales. 223-244. Donosti: Ankulegi.

Descola, P. 1998. "Las cosmologías de los indios del Amazonas". Zainak: 219-227.

Descola, P. 2007. "Posface. Les coulisses de la natura". Cahiers d'antropologie sociale 3: 123-127.

Descola, P. y G. Pálsson (eds.). 1996. Nature and Society. Anthropological perspectives. Londres: Routledge.

Durán, I. 2002. "Turismo y recreación medioambiental", en Santana, A. y S. Rodríguez (coords.), Recreaciones medio-ambientales, politicas de desarrollo y Turismo. Barcelona: FAAEE.

Durán, I. 2006. "Creando y recreando el entorno: de espacios naturales protegidos a comarcas sostenibles", en Valcuente del Río, J. y L. Cardia (coords.), Territorializaiçao, Meio Ambiente e Desenvolvimiento no Brasil e na Espanha, 381-400. Brasil: Universidade Federal do Acre.

Eder, K. 1996. The Social Construction of Nature. A Sociology of Ecological Enlightenment. Londres: Sage.

Escobar, A. 1995. "El desarrollo sostenible: Diálogo de discursos". Ecología Política 9: 7-27.

Escobar, A. 1996. "Constructing Nature. Elements for a postructural political ecology", en Peet, R., y M. Watts (eds.), Liberation ecologies. Londres: Routledge.

EUROPARC. 2008. Anuario EUROPARC-España del estado de los espacios naturales protegidos 2007. Madrid: Fundación Fernando González-BBV. 
Evaluación de los ecosistemas del milenio, 2004. Informe de síntesis de evaluación de los ecosistemas del Milenio. http://www.millenniumassessment.org

Fernández, J. 1993. "La misión de la metáfora en la cultura expresiva". Papeles de filosofía 12 (1).

Fernández, J. 1999. El ecologismo español. Madrid: Alianza.

Florido, D. 2005. "Los molinos de viento de Trafalgar. Paradojas, ambivalencias y conflictos respecto a las relaciones humano-ambientales en el sur de Andalucía", en Pascual, J. y D. Florido (coords.), ¿Protegiendo los recursos?: 209-242. Sevilla: FAAEE.

Florido, D. y J. Clavero. 2008. "La reserva de la Biosfera Intercontinental del Mediterráneo", en Beltran, O., J. Pascual y I. Vaccaro (coords.). Patrimonialización de la naturaleza. El marco social de las políticas ambientales: 115-130. Donosti: Ankulegi.

Frigolé, J. 2006. "Globalización y producción de localidad en un valle del Alt Urgell. Modelo interpretativo y síntesis etnográfica", en Frigolé, J. y X. Roigé (eds), Globalización y localidad: perspectiva etnográfica: 17-32. Barcelona: Publicacions i Edicions UB.

Frigolé, J. 2007. "Los modelos de lo rústico, lo salvaje y lo silvestre y la identidad de una valle del entorno de Cadî", en Vaccaro, I y O. Beltran (eds.), Ecología política de los Pirineos. Estado, Historia y Paisaje: 157-171. Barcelona: Garsineu Edicions.

Frigolé, J. y X. Roigé (coords.) 2006. Globalización y localidad: perspectiva etnográfica. Barcelona: Publicacions i Edicions UB.

Hames, R. 2007. "The ecologically noble savage debate". Annual Review of Anthropology 36: $177-190$.

Haraway, D. 1995. Ciencia, cyborgs y mujeres. La reinvención de la naturaleza. Madrid: Cátedra.

Hernández, E. 2008. "De parques naturales a parques urbanos. Turismo patrimonialización del territorio, en áreas protegidas" en Beltran, O., J. Pascual y I. Vaccaro (coords.). Patrimonialización de la naturaleza. El marco social de las políticas ambientales: 8396. Donosti: Ankulegi.

Hernández, J. 2005. "Activando la memoria, mirando al futuro. Patrimonialización de un oficio perdido y dinamización”, en Pascual, J. y D. Florido (coords.). ¿Protegiendo los recursos?: 193-208. Sevilla: FAAEE.

Hobsbawm, E. y T. Ranger. 2002. La invención de la tradición. Barcelona: Crítica.

Hornborg, A. y G. Pálsson. 2000. Negotiating Nature: Culture, Power, and Environmental Argument. Lund: Lund University Press.

Igoe, J. y D. Brockington. 2007. "Neoliberal Conservation: A Brief Introduction". Conservation and Society 5 (4): 432-449

IPCC. 2007. Cambio climático 2007. Informe de síntesis. http://www.ipcc.ch/pdf/assess ment-report/ar4/syr/ar4_syr_sp.pdf

Kottak, C. 1999. "The New Ecological Anthropology". American Anthropologist 101 (1): 23-35.

Krech, S. 2005. "Reflections on Conservation, Sustainability, and Environmentalism in Indigenous North America". American anthropologist 107 (1): 78-86.

Latour, B. 1993. Nunca hemos sido modernos. Ensayo de antropología simétrica. Madrid: Debate.

Latour, B., y S. Woolgar. 1995. La vida en el laboratorio. La construcción de los hechos científicos. Madrid: Alianza.

Lemos, C. y A. Agrawal. 2006. "Environmental governance". Annual Review of Anthropo$\log$ 31: 297-325.

Lowenthal, D. 1998. El pasado es un país extraño. Barcelona: Akal.

Maffesoli, M. 1993. El conocimiento ordinario. Compendio de sociología. México: FCE. 
Maffesoli, M. 1997. Elogio de la razón sensible. Una visión intuitiva del mundo contemporáneo. Barcelona: Paidós.

Milton, K. 2001. "Ecologías: antropología, cultura y entorno". Revista Internacional de Ciencias Sociales 154: 86-115.

Mulero, A. 2001. La protección de los espacios naturales en España. Madrid: Mundi-Prensa.

Muñoz, J. C. 2006. Turismo y sostenibilidad en espacios naturales protegidos. Tesis doctoral. Universitat de Girona.

Pálsson, G. 1996. "Human-environmental relations: orientalism, paternalism and communalism”, en Descola, P. y G. Pálsson (eds.), Nature and Society. Anthropological perspectives: 63-81. Londres: Routledge.

Pascual, J. 2002. "Del 'mar es de todos al mar reservado': turistas, poblaciones de pescadores y reservas marinas en Canarias", en Santana, A. y S. Rodríguez (coords.), Recreaciones medio-ambientales, politicas de desarrollo y Turismo. Barcelona: FAAEE.

Pascual, J. y R. De la Cruz. 2008. "Los espacios marinos en España: ¿Nuevas formas institucionales para las estrategias de apropiación?", en Beltran, O., J. Pascual e I. Vaccaro (coords.). Patrimonialización de la naturaleza. El marco social de las politicas ambientales: 199-222. Donosti: Ankulegi.

Pascual, J. y D. Florido (coords.). 2005. ¿Protegiendo los recursos? Áreas protegidas, poblaciones locales y sostenibilidad. Sevilla: Fundación Monte.

Pascual, J., J. Batista y R. De la Cruz. 2005. "Reservas marinas, participación y desarrollo sostenible" en Pascual, J. y D. Florido (coords.). ¿Protegiendo los recursos?: 45-62. Sevilla: FAAEE.

Peterson, R., D. Russell, P. West y P. Brosius. 2008. "Seeing (and Doing) Conservation Through Cultural Lenses". Environmental Management (On line).

Petras, J. y H. Veltmeyer. 2002. El imperialismo en el siglo XXI. La globalización desenmascarada. Madrid: Popular.

PNUD. 2007. Informe sobre el desarrollo bumano 2007-2008. La lucha contra el cambio climático. http://hdr.undp.org/en/media/HDR_20072008_SP_Complete.pdf

PNUMA. 2007. Perspectivas del Medio Ambiente Mundial. Geo-4. Medio Ambiente para el desarrollo. http://www.oei.es/decada/GEO-4_Report_Full_ES.pdf

Prats, Ll. 1997. Antropología y patrimonio. Barcelona, Ariel.

Quintero, V., J. Valcuente y J. Cortés. 2008. "Contemplar o vivir. Símbolos y legitimaciones en un espacio protegido", en O. Beltran, J. Pascual e I. Vaccaro (coords.). Patrimonialización de la naturaleza. El marco social de las políticas ambientales: 65-82. Donosti: Ankulegi.

Riechmann, J. y F. Fernández Buey. 1994. Redes que dan libertad. Barcelona: Paidós.

Rifkin, J. 1980. Entropía. Hacia el mundo invernadero. Barcelona: Urano

Rodrigues, K. y J. Pascual. 2008. "Patrimonialización de la naturaleza y turismo", en Beltran, O., J. Pascual e I. Vaccaro (coords.). Patrimonialización de la naturaleza. El marco social de las políticas ambientales: 115-130. Donosti: Ankulegi.

Roigé, X. 2006. "Identidad, frontera y turismo en el Valle de Arán", en Frigolé, J. y X. Roigé (eds). Globalización y localidad: perspectiva etnográfica: 33-60. Barcelona: Edicions UB.

Roigé, X. y F. Estrada. 2007. "El parque Natural del Montseny. Gestión y evolución del paisaje", en Vaccaro, I. y O. Beltran (eds.). Ecología política de los Pirineos. Estado, Historia y Paisaje: 223-239. Barcelona: Garsineu Edicions.

Sánchez Garrido, R. 2008. "Construcción física y construcciones ideológicas", en Beltran, O., J. Pascual e I. Vaccaro (coords.). Patrimonialización de la naturaleza. El marco social de las políticas ambientales: 131-148. Donosti: Ankulegi. 
Santamarina, B. 2005a. "La patrimonialización de la naturaleza: figuras y discursos", en Pascual, J. y D. Florido (eds.), ¿Protegiendo los recursos? Áreas protegidas, poblaciones locales y sostenibilidad: 9-44. Sevilla: Fundación Monte.

Santamarina, B. 2005b. "Una aproximación al patrimonio cultural", en G. Hérnández, B. Santamarina, A. Moncusí y M. Albert. La memoria construida: 21-51. Valencia: Tirant Lo Blanch.

Santamarina, B. 2006. Ecología y poder. El discurso medioambiental como mercancía. Madrid: Libros de la Catarata.

Santamarina, B. 2008a. "Antropología y medio ambiente. Revisión de una tradición y nuevas perspectivas de análisis en la problemática ecológica”. AIBR 3 (2): 144-154.

Santamarina, B. 2008b. "Patrimonialización de la naturaleza en la comunidad valenciana. Espacios, ironías y contradicciones", en Beltran, O., J. Pascual e I. Vaccaro (coords.). Patrimonialización de la naturaleza. El marco social de las políticas ambientales: 27-44. Donosti: Ankulegi.

Santana, A. y S. Rodríguez (coords.). 2002. Recreaciones medio-ambientales, políticas de desarrollo y Turismo. Barcelona: FAAEE.

Selmi, A. y V. Hirtzel. 2007. "Introduction. Parquer la nature". Cabiers d'antropologie sociale, 3: 9-12.

Shapin, S. 2000. La Revolución científica. Una interpretación alternativa. Barcelona: Paidós.

Stevens, S. 1997. "The legacy of Yellowstone", en S. Stevens (ed.). Conservation through cultural survival: indigenous people and protected areas: 13-32. Washington: Island Press.

Strathern, M. 1980. "No nature, no culture: the Hagen case", en MacCormack, C. y M. Strathern (eds). Nature, culture and gender: 174-222. Nueva York: Cambridge University Press.

UICN. 2005. Beneficios más allá de las fronteras. Actas del V Congreso Mundial de Parques de la UICN. Gland, Suiza, y Cambridge: UICN.

Vaccaro, I. 2005. "Property Mosaic and State-making: Governmentality, Expropriation and Conservation in the Pyrenees". Journal of Ecological Anthropology 9: 4-19.

Vaccaro, I. 2006a. "Valles postindustriales. La urbanización de las montañas y sus consecuencias sociales y ecológicas", en Frigolé, J. y X. Roigé (eds.), Globalización y localidad: perspectiva etnográfica: 61-90. Barcelona: Publicacions i Edicions UB.

Vaccaro, I. 2006b. "Postindustrial valleys: the Pyrenees as a reinvented landscape". Social Anthropology 14 (3): 361-376.

Vaccaro, I. y O. Beltran (eds.). 2007. Ecología politica de los Pirineos. Estado, Historia y Paisaje. Barcelona: Garsineu Edicions.

Vaccaro, I. y O. Beltran. 2007. "Consuming Space, Nature and Culture: Patrimonial Discussions in the Hyper-Modern Era". Tourism Geographies 9 (3): 254-274.

West, P. y D. Brockington. 2006. "An Anthropological Perspective on Some Unexpected Consequences of Protected Areas". Conservation Biology 20 (3): 609-616.

West, P., J. Igoe y D. Brockington. 2006. "Parks and peoples: The social impact of protected areas". Annual Review of Anthropology 35: 251-277.

Woolgar, S. 1991. Ciencia: Abriendo la caja negra. Barcelona: Anthropos.

Fecha de recepción: 10 de noviembre de 2008

Fecha de aceptación: 10 de febrero de 2009

RDTP, vol. LXIV, n. ${ }^{\circ}$ 1, pp. 297-324, enero-junio 2009, ISSN: 0034-7981, eISSN: 1988-8457, doi: 10.3989/rdtp.2009.78 